\title{
Modeling and control of a doubly fed induction machine (DFIM)
}

\author{
Badr M. Alshammari* \\ College of Engineering, University of Hail, Hail City, Saudi Arabia
}

\section{A R T I CLE INFO}

Article history:

Received 4 June 2016

Received in revised form

7 September 2016

Accepted 15 September 2016

\section{Keywords:}

Vector control

Doubly fed asynchronous machine

Pulse width modulation

PI controller

\begin{abstract}
A B S T R A C T
In this paper, the behavior of a doubly fed induction machine (DFIM) is presented. It is functioning in mode motor and of which the rotor and the stator are fed through the intermediary of a chain of conversion of AC/AC type. The latter is composed of a converter AC/DC (three phase rectifier to diodes), a LC filter and a second converter DC/AC (inverter ordered while running to Modulation of Width of impulses). So, we adopted a strategy of survey having for objective to make servitude quickly of the DFIM while applying the order to flux oriented statorique led then of a regulating PI.
\end{abstract}

(C) 2016 The Authors. Published by IASE. This is an open access article under the CC BY-NC-ND license (http://creativecommons.org/licenses/by-nc-nd/4.0/).

\section{Introduction}

Currently, several studies are oriented towards the study of the doubly fed induction machine that has a solution for high power drives and variable speed operation and it ensures a very low speed $\mathrm{Cu}$ et al., 2013). In addition, the variable speed drive is a multidisciplinary field of electrical engineering, which brings together diverse expertise in several sectors: electrical machinery, power electronics, control, etc. (Akagi and Sato, 2002). Thus, the association of double-fed asynchronous machines with static converters can provide different control strategies. However, order one of these machines remains a delicate operation, since it presents problems of command because of the strong coupling between the flux and torque. To overcome this problem, we came to the vector control which brings the behavior of the DFIM to that of a DC motor. Thus, regulators most commonly used for the purposes of this order are PI type with its simple implementation and ease of synthesis. Nevertheless, the limitation of performance offered by the regulator has encouraged researchers to find a replacement who found in artificial intelligence. Among the branches of this technique, we chose to work with fuzzy logic whose foundations were established in 1965 by Lotfi Zadeh at the University of California Berekley, which introduces the concept of fuzzy set (Ledesma and Usaola, 2004). In order to confirm the contribution of the use of a fuzzy controller compared to conventional PI, we

* Corresponding Author.

Email Address: badr ms@hotmail.com (B. M. Alshammari) https://doi.org/10.21833/ijaas.2016.09.002

2313-626X/@ 2016 The Authors. Published by IASE.

This is an open access article under the CC BY-NC-ND license

(http://creativecommons.org/licenses/by-nc-nd/4.0/) represented the results of simulating the behavior of DFIM controlled stator flux oriented and conducted a fuzzy controller of speed.

\section{Modeling of doubly fed induction machine}

The use of DFIM in the field of variable speed drive uses the command, and to this end, a mathematical model of the process is then essential (Akagi and Sato, 2002). Thus the determination of such a model allows us to simulate the behavior of the machine in transient and lead to an order following a control scheme (Morel et al., 1998) we will study later. The dynamic model of the DFIM is reflected in the Landmark Park, linked to the rotating field by the equations as follows:

$$
\begin{aligned}
& \Phi_{r d}=\mathrm{V}_{r d}-\frac{R_{r}}{L_{r}} \Phi_{r d}+\frac{R_{r}}{L_{r}} M I_{s d}+\left(\omega_{s}-\omega\right) \Phi_{r q} \\
& \Phi_{r q}=\mathrm{V}_{r q}-\frac{R_{r}}{L_{r}} \Phi_{r q}+\frac{R_{r}}{L_{r}} M I_{s q}-\left(\omega_{s}-\omega\right) \Phi_{r d} \\
& I_{s d}=\frac{1}{\sigma L_{s}}\left(V_{s d}-I_{s d}\left(R_{s}+\frac{M^{2}}{L_{r}} \frac{R_{r}}{L_{r}}\right)+\sigma \omega_{s} L_{s} I_{s q}+\right. \\
& \frac{M}{L_{r}} \frac{R_{r}}{L_{r}} \Phi_{r d}+\frac{M}{L_{r}} \omega \Phi_{r q} \\
& I_{s q}=\frac{1}{\sigma L_{s}}\left(V_{s q}-I_{s q}\left(R_{s}+\frac{M^{2}}{L_{r}} \frac{R_{r}}{L_{r}}\right)-\sigma \omega_{s} L_{s} I_{s d}+\right. \\
& \frac{M}{L_{r}} \frac{R_{r}}{L_{r}} \Phi_{r d}+\frac{M}{L_{r}} \omega \Phi_{r q} \\
& \Omega=\frac{p M}{J}\left(I_{s q} I_{r d}-I_{s d} I_{r q}\right)-\frac{C_{r}}{J}-\frac{f}{J} \Omega
\end{aligned}
$$

\section{Strategy for the control of DFIM}

The structure of the double-fed asynchronous machine has the advantage of carrying out an order by several methods and structures, depending on the mode of operation, the variable order and the application domain (Wu et al., 2013). In our work, we studied the structure of which the DFIM is controlled from two inverters: one to the other 
stator and the rotor. Each of these two converters is powered by its own rectifier through an LC filter. To improve the performance of the inverter, use the pulse width modulation (PWM). This control technique allows defining the instants of the switches (Ottersten, 2000). Its principle consists in regulating the amplitude and fundamental frequency signal and the rejection of harmonics whose amplitude is important, of MLI techniques, the best known are:

- PWM control strategy with current or hysteresis current modulation.

- PWM with carrier-modulation or natural.

- Vector PWM.

- PWM with harmonic-criteria.

In our study, we focus on the modulation hysteresis current. This control strategy is simple and effective because it allows us to both maintain the current close to their references in a band known as hysteresis tolerance band whose role is to impose the real ripple currents, and control the switches of the inverter and control the currents in the stator phases of the machine.

\section{Vector control}

It is important to remember that the difficulty of controlling a DFIM is prompted by the fact that the electromagnetic torque from the interaction between charged currents in the stator windings and currents induced in those rotor (Monroy and Alvarez-Icaza, 2006). The application of vector control introduced by Blaschke in 1972 was a breakthrough in controlling the induction machine. It leads us to decouple the rotor and the stator frame (Ledesma and Usaola, 2004). The principle of vector control is then in fact brings the behavior of the DFIM to the MCC with a decoupling between flux and torque, is existed in nature.

The vector control can be classified into two types according to the method of flow direction (direct or indirect):

- Vector control directly.

- Vector control indirectly.

The indirect method can be considered as the easiest to implement and widely used (Pena et al., 2002). In this work, use this method, given its huge advantage in the fact that the amplitude does not flow, but only its position. Specifically, we will focus on the orientation of stator flux. Stator flux orientation along the axis line is used to write:

$\Phi_{s d}=\Phi_{s}$ et $\quad \Phi_{s q}=0$

We get to write the electromagnetic torque as given by Eq. 7 .

$\mathrm{C}_{e m}=\frac{p M}{L_{s}} \Phi_{s} I_{r q}$

It should be noted that in the expression, already established, the two components of rotor current and intercede with the first controls the flow and the other controls the torque.

This means that there are two action variables (Poller, 2003) and the couple DFIM becomes similar to that of MCC. The voltage equation of stator phase is given by:

$v_{s}=R_{s} i_{s}+\frac{d \Phi_{s}}{d t}$

For a machine of high or medium power, and stator flux oriented, we get:

$V_{s d}=0$

$V_{s q}=v_{s}=\omega_{s} \Phi_{s}$

Taking into account equations (9) and (10), the active power and reactive that is given by the two relations (11) and (12).

$P_{s}=V_{s q} I_{s q}$

$Q_{s}=V_{s q} I_{s d}$

By choosing to work with a stator power factor very close to unity, it will be mandatory to have a zero reactive power to the stator. This amounts to imposing a stator reference current Isd zero.

$I_{\text {sdref }}=0$

We arrive at the instruction set of the electromagnetic torque.

$C_{\text {emref }}=p M I_{\text {rdref }} I_{\text {sqref }}$

from where:

$I_{\text {sqref }}=\frac{C_{\text {em ref }}}{p M I_{\text {rd ref }}}$

with

$I_{\text {sdref }}=\frac{\Phi_{\text {sref }}}{M}$

As for the current $\mathrm{I}_{\mathrm{rq}}$ reference, it can be written in this form:

$I_{\text {rq ref }}=-\frac{\mathrm{L}_{s}}{M} I_{\text {sqref }}$

From relations (13), (15), (16) and (17), we then come to find references to different currents needed to control hysteresis inverters. The speed control will be provided by a PI controller responsible for providing the electromagnetic torque reference. Fig.3. implements the block diagram of the speed control of the DFIM stator flux oriented controlled. This command is mainly based on the loop speed control. The latter gives us, at its output, the torque (EMC ref) to calculate the reference current (Isq ref).

As to current guidelines, they allow the current control of two inverters (side stator and rotor). By accessing the inverse Park transformation, one arrives at the reference currents in the natural landmark that represent the instructions provided to 
the PWM stage. This stage PWM hysteresis role is to provide controls the switches of each inverter.

With regard to the speed control used, it should determine the electromagnetic torque reference in order to maintain speed to its reference (Ledesma and Usaola, 2004). To do this, it takes as input the speed reference and the measured one. In our work, we used a PI controller due to its simplicity and speed of handling it offers.

The transfer function of such a controller is given by the following equation:

$$
H(p)=k_{p}+\frac{K_{I}}{P}
$$

\section{Application of the vector control conducted a pi controller for DFIM}

When simulating the behavior of the DFIM stator flux oriented and using a PI controller for speed, we obtained the results shown in nest figures (Figs. 1 to $6)$.

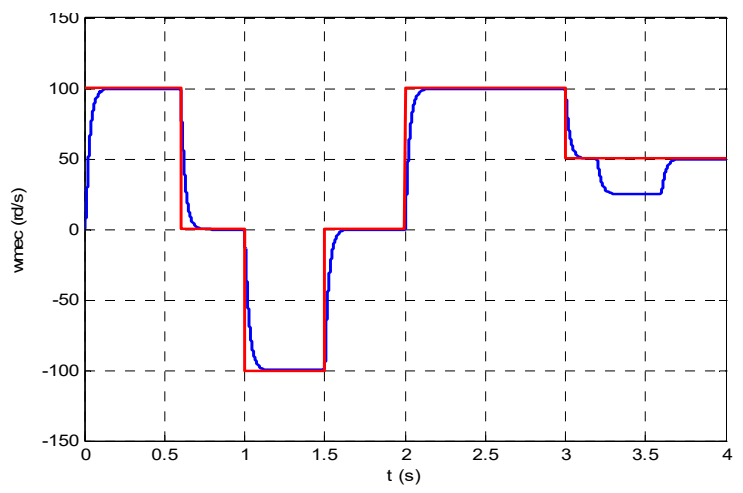

Fig. 1: Mechanical speed and its reference

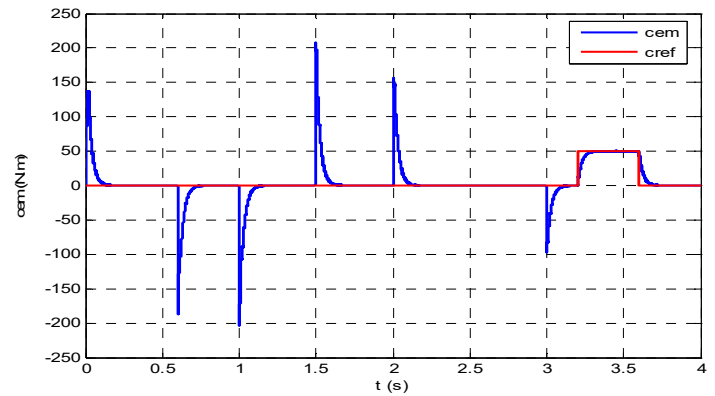

Fig. 2: Electro-magnetic torque

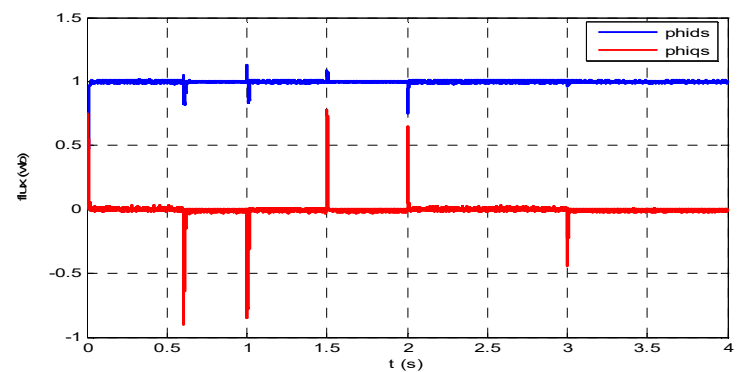

Fig. 3: The stator flux

The analysis of these results shows that the response speed of 0.196 is delayed about every time we vary the set point during start unloading. During the phase of insertion torque, the actual speed of the machine moves away from its reference of considerable value; in addition to changes in set point speed cause large peaks (coming up to $200 \mathrm{Nm}$ ) for the electromagnetic torque.

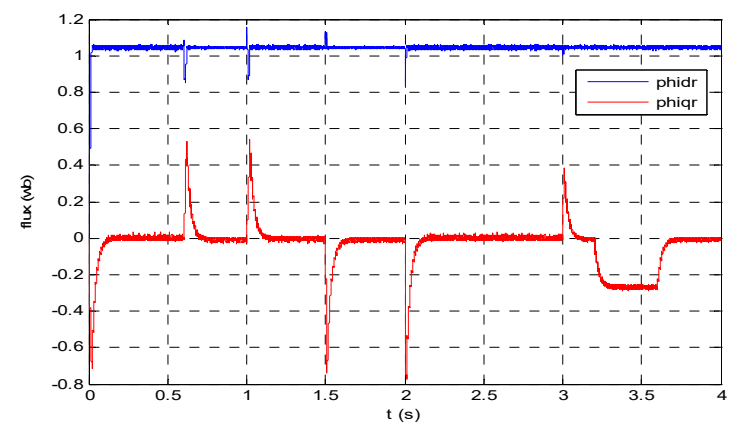

Fig. 4: The rotor flux

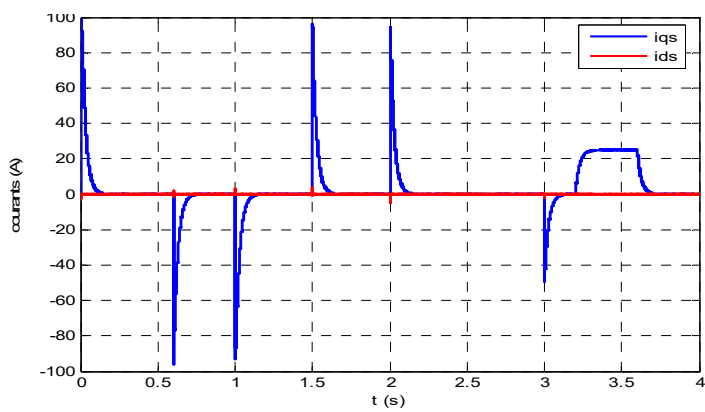

Fig. 5: The stator current

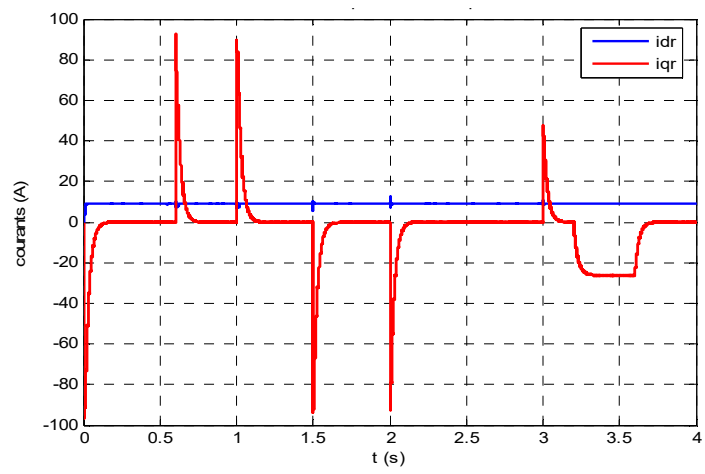

Fig. 6: The rotor currents

Let's notice, by examining the curves representing the variation of the quadrature component of stator current and the rotor current, these two quantities undergo unwanted peaks during the transition phases of the reference speed. For the behavior of the machine magnetic point of view, we find the response of the rotor flux on the axis "q" peaks seen on the quadrature component of the current frame. As for the stator flux on the same axis, he says the direction vector applied to the DFIM, however, he sustained peak varies very fast when the reference speed. Thus, there is also the impact of torque on the magnetic state of the machine. This can be judged from the evolution curve of $\Phi_{r q}$. In conclusion, the curves representing the evolution of electrical, magnetic and mechanical 
ones, we can conclude the lack of the use of PI (especially point of view dynamic performances).

\section{Conclusion}

Within this article, we performed a study on the vector control by stator flux orientation of the DFIM with emphasis on the improvement made by a fuzzy controller, capable of handling the imprecise, the uncertain, the wave and the non-linear models, the performance of this machine compared to a conventional PI controller which can lose its strength vis-à-vis an external perturbation. Finally, it should be noted that the work done on controlling the DFIM leads us to propose, as work opportunities that can be achieved in future studies, the control of the DFIM through other strategies (DTP, sliding mode ...), the practical implementation of the strategy studied using unconventional methods (neural networks, genetic algorithms ...) as well as controlling the DFIM using the DSP interface.

\section{References}

Akagi H and Sato H (2002). Control and performance of a doubly-fed induction machine intended for a flywheel energy storage system. IEEE Transactions on Power Electronics, 17(1): 109116.

Ledesma P and Usaola J (2004). Effect of neglecting stator transients in doubly fed induction generators models. IEEE transactions on energy conversion, 19(2): 459-461.

Monroy A and Alvarez-Icaza L (2006). Passivity based control of a DFIG wind turbine. In the IEEE American Control Conference, Minnesota, USA: 1050-1055.

Morel L, Godfroid H, Mirzaian A and Kauffmann JM (1998). Double-fed induction machine: converter optimization and field oriented control without position sensor. IEE Proceedings-Electric Power Applications, 145(4): 360-368.

Ottersten R (2000). Vector control of a double-sided PWM converter and induction machine drive. Chalmers University of Technology, Goteborg, Sweden, Licentiate.

Pena R, Cardenas R, Asher GM, Clare JC, Rodriguez J and Cortes P (2002). Vector control of a dieseldriven doubly fed induction machine for a standalone variable speed energy system. In the $28^{\text {th }}$ Annual IEEE Conference of the Industrial Electronics Society (IECON 02): 985-990.

Poller MA (2003). Doubly-fed induction machine models for stability assessment of wind farms. In the IEEE conference of the Power Tech, Bologna, Italy: 23-26.

Wu FK, Yeh TJ and Huang CF (2013). Motor control and torque coordination of an electric vehicle actuated by two in-wheel motors. Mechatronics, 23(1): 46-60. 